\title{
$\theta$ OPEN ACCESS \\ The relationship between infliximab concentrations, antibodies to infliximab and disease activity in Crohn's disease
}

\author{
Niels Vande Casteele, ${ }_{1}^{1,2,3}$ Reena Khanna, ${ }^{3}$ Barrett G Levesque, ${ }^{2,3}$ Larry Stitt, $^{3}$ \\ G Y Zou, ${ }^{3}$ Sharat Singh, ${ }^{4}$ Steve Lockton, ${ }^{4}$ Scott Hauenstein, ${ }^{4}$ Linda Ohrmund, ${ }^{4}$ \\ Gordon R Greenberg, ${ }^{5}$ Paul J Rutgeerts, ${ }^{6}$ Ann Gils, ${ }^{1}$ William J Sandborn, ${ }^{2}$ \\ Séverine Vermeire, ${ }^{6}$ Brian G Feagan $^{3}$
}

\begin{abstract}
${ }^{1} \mathrm{KU}$ Leuven Department of Pharmaceutical and Pharmacological Sciences, Leuven, Belgium

${ }^{2}$ Division of Gastroenterology, University of California San Diego, La Jolla, California, USA ${ }^{3}$ Robarts Clinical Trials, Western University, London, Ontario, Canada

${ }^{4}$ Prometheus Laboratories, Inc., San Diego, California, USA ${ }^{5}$ University of Toronto, Mount Sinai Hospital, Toronto, Ontario, Canada

${ }^{6} \mathrm{KU}$ Leuven Department of Clinical and Experimental Medicine, Leuven, Belgium
\end{abstract}

\section{Correspondence to}

Brian G Feagan, Department of Medicine, Robarts Research Institute, University of Western Ontario, PO Box 5015, 100 Perth Drive, London, Ontario N6A 5K8, Canada;

Brian.Feagan@robartsinc.com

Received 20 June 2014 Revised 3 September 2014 Accepted 26 September 2014 Published Online First 21 October 2014

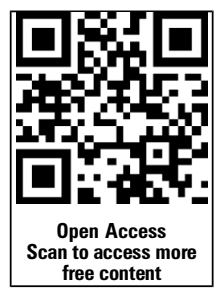

\section{(a) CrossMark}

To cite: Vande Casteele $\mathrm{N}$, Khanna R, Levesque BG, et al. Gut 2015;64: $1539-1545$

\section{ABSTRACT}

Objective Although low infliximab trough concentrations and antibodies to infliximab (ATI) are associated with poor outcomes in patients with Crohn's disease (CD), the clinical relevance of ATI in patients with adequate infliximab concentrations is uncertain. We evaluated this question using an assay sensitive for identification of ATI in the presence of infliximab.

Design In an observational study, 1487 trough serum samples from 483 patients with CD who participated in four clinical studies of maintenance infliximab therapy were analysed using a fluid phase mobility shift assay. Infliximab and ATI concentrations most discriminant for remission, defined as a C-reactive protein concentration of $\leq 5 \mathrm{mg} / \mathrm{L}$, were determined by receiver operating characteristic curves. A multivariable regression model evaluated these factors as independent predictors of remission.

Results Based upon analysis of 1487 samples, $77.1 \%$ of patients had detectable and $22.9 \%$ had undetectable infliximab concentrations, of which $9.5 \%$ and $71.8 \%$, respectively, were positive for ATI. An infliximab concentration of $>2.79 \mu \mathrm{g} / \mathrm{mL}$ (area under the curve $(A \cup C)=0.681 ; 95 \% \mathrm{Cl} 0.632$ to 0.731$)$ and $\mathrm{ATI}$ concentration of $<3.15 \mathrm{U} / \mathrm{mL}(A \cup C=0.632 ; 95 \% \mathrm{Cl}$ 0.589 to 0.676 ) were associated with remission. Multivariable analysis showed that concentrations of both infliximab trough (OR 1.8; $95 \% \mathrm{Cl} 1.3$ to 2.5 ; $\mathrm{p}<0.001)$ and ATI (OR 0.57; $95 \% \mathrm{Cl} 0.39$ to 0.81; $p=0.002$ ) were independent predictors of remission. Conclusions The development of ATI increases the probability of active disease even at low concentrations and in the presence of a therapeutic concentration of drug during infliximab maintenance therapy. Evaluation of strategies to prevent ATI formation, including therapeutic drug monitoring with selective infliximab dose intensification, is needed.

\section{INTRODUCTION}

Over the past decade, considerable evidence has accumulated that sensitisation to biological drugs is an important clinical problem. In 2003, Baert and colleagues performed a prospective cohort study of 125 patients with Crohn's disease (CD), which identified that the presence of an antibody to infliximab (ATI) concentration $\geq 8 \mu \mathrm{g} / \mathrm{mL}$ was associated

\section{Significance of this study}

What is already known on this subject?

- C-reactive protein is a marker of disease activity in patients with Crohn's disease.

- Low or undetectable serum trough concentrations of infliximab (IFX) are associated with worse clinical outcomes.

- Antibodies to infliximab (ATI) increase the clearance of drug and are an important cause of low-serum IFX trough concentrations.

\section{What are the new findings?}

- Based on a combined analysis of patient-level data from four studies that evaluated 483 patients with Crohn's disease using a fluid phase mobility shift assay, IFX trough concentrations $>2.79 \mu \mathrm{g} / \mathrm{mL}$ during maintenance therapy were associated with remission as measured by C-reactive protein concentration.

- Detectable ATI were associated with greater disease activity as measured by C-reactive protein concentration even in the presence of an adequate IFX trough concentration.

- ATI impair the drug's activity through an alternative mechanism than only by affecting its clearance.

How might it impact on clinical practice in the foreseeable future?

- These results support the role of therapeutic drug monitoring in patients with Crohn's disease receiving IFX. We speculate that if the presence of ATI has a negative effect on the pharmacodynamics of IFX independent of the trough concentration, other pharmacokinetics determinants such as the area under the curve and maximum serum concentration $\left(C_{\max }\right)$ of the drug might also be important predictors of clinical efficacy. Therapeutic drug monitoring with dose intensification in patients with undetectable or low IFX trough concentrations should be evaluated as a strategy to prevent development of ATI. 
with shorter time to relapse compared with patients with lowtitre ATI. ${ }^{1}$ Furthermore, patients with ATI had a greater risk of hypersensitivity reactions. Although subsequent studies have attempted to define an ATI concentration that correlates with clinical outcomes, ${ }^{2}{ }^{3}$ differences in assay design, ${ }^{4} 5$ the sometimes transient nature of ATI expression ${ }^{367}$ and the inability of conventional assays to measure ATI in the presence of drug have made identification of such a relationship problematic. Nevertheless, a recent meta-analysis that evaluated 1378 patients with IBD who received treatment with infliximab (IFX) showed that the pooled risk ratio for loss of clinical response in patients with ATI was 3.2 (95\% CI 2.0 to 4.9 ; $\mathrm{p}<0.0001)$ in comparison with control patients without ATI. ${ }^{8}$ Considerable evidence exists that higher IFX concentrations are associated with greater clinical efficacy in patients with IBD. ${ }^{2}{ }^{9-15}$ For example, in ACCENT I, ${ }^{16}$ a multicentre trial that evaluated IFX induction therapy in patients with active $\mathrm{CD}$, patients who failed to respond to therapy had lower serum IFX concentrations than those with a sustained response $(1.9$ and $4.0 \mu \mathrm{g} / \mathrm{mL}$, respectively; $\mathrm{p}=0.03) .{ }^{17}$ Collectively, these data indicate that both presence of ATI and low IFX concentrations are associated with worse clinical outcomes. As a consequence, the use of therapeutic drug monitoring (TDM) has been advocated to improve clinical decision making in patients with a secondary loss of response to IFX. ${ }^{18} 19$ These observations also hold out the possibility that dose optimisation based on TDM during induction, prior to recurrence of symptoms, and possibly prior to ATI formation might result in better outcomes. ${ }^{20}{ }^{21}$ However, analysis of the impact of ATI on IFX pharmacokinetics has been hindered by the inability of most assays to detect ATI in the presence of IFX. Thus, it has not been possible to determine whether the negative effects of ATI on clinical efficacy are solely the consequence of low-trough drug concentrations (i.e. whether patients with ATI and low drug concentrations are entirely a subset of patients with low-drug concentrations) or whether ATI might also impair other measures of drug exposure, such as the maximum serum concentration $\left(\mathrm{C}_{\max }\right)$ or the area under the concentration time curve (AUC), which are critical to the pharmacodynamics of IFX (even when drug is present). Therefore, an enhanced understanding of the relevance of ATI in patients with a detectable serum concentration of IFX is potentially important.

Based on these considerations, we used a homogenous mobility shift drug-tolerant assay able to measure ATI in the presence of IFX to evaluate the relationship between serum IFX trough concentration, ATI concentration and disease activity in a large population of patients with CD.

\section{MATERIALS AND METHODS Study objectives}

Our study had two objectives. First, we wished to determine the IFX trough concentration during maintenance therapy that best correlated with $\mathrm{C}$-reactive protein (CRP)-defined remission as a surrogate for clinical remission. A CRP concentration of $\leq 5 \mathrm{mg} / \mathrm{L}$ was defined as remission. CRP was chosen to define disease activity, in distinction to clinical symptoms, because numerous studies have demonstrated that a poor correlation exists between symptoms and inflammation defined by colonoscopy, serum acute-phase reactants such as CRP or faecal biomarkers such as calprotectin. ${ }^{22} 23$ A second goal was to evaluate the relationship between CRP concentration as a measure of disease activity, the IFX trough concentration and the presence of ATI in four distinct groups of patients: (1) IFX trough concentration $\geq 3 \mu \mathrm{g} / \mathrm{mL}$ and ATI negative; (2) IFX trough concentration $<3 \mu \mathrm{g} / \mathrm{mL}$ and ATI negative; (3) IFX trough concentration $\geq 3 \mu \mathrm{g} / \mathrm{mL}$ and ATI positive and (4) IFX trough concentration $<3 \mu \mathrm{g} / \mathrm{mL}$ and ATI positive. The rationale for these subgroup analyses is based on the hypothesis that the indirect correlation between IFX and disease activity differs by ATI status. Specifically, we wished to determine whether ATI was a predictor of disease activity independent of IFX trough concentration.

\section{Study design and conduct}

Assays were performed on 1487 trough serum samples from 483 patients with CD treated with maintenance IFX therapy who had previously participated in one of four prospective randomised controlled trials or cohort studies: the COMMIT trial $^{24}$ the Leuven transient ATI study, ${ }^{3}$ the Canadian Multicentre study ${ }^{25}$ and the Leuven antimetabolite withdrawal study. $^{26}$

\section{Study population and evaluations}

Trough serum samples were obtained during each study. From both of the Leuven studies, the only samples included were those available at time that the current study was designed and implemented. The COMMIT study ${ }^{24}$ was a randomised controlled trial that evaluated the efficacy of combination therapy with methotrexate and IFX. The Leuven transient ATI study ${ }^{3}$ examined the effect of transient ATI formation on IFX pharmacokinetics and clinical response. The Canadian Multicentre study $^{25}$ was a prospective analysis of the relationship between IFX concentrations, ATI concentrations and clinical disease activity in patients receiving maintenance therapy. The fourth study $^{26}$ evaluated the efficacy of continued antimetabolite therapy in patients, after receiving combination therapy with IFX during the first six months of therapy. These parent studies enrolled adult patients with moderate-to-severe CD. Demographic data collected included the age at diagnosis, the age at first IFX infusion and the use of concomitant treatment with azathioprine or methotrexate, as well as the serum sample collection date. Each of these studies collected trough serum samples for analysis of serum IFX, ATI and CRP concentration. Serum CRP was measured with the Vascular Injury Panel 2 (human) V-PLEX Kit (Meso Scale Discovery, Rockville, Maryland, USA) on the MSD platform (Meso Scale Discovery, Rockville, Maryland, USA) with a lower limit of quantitation (LLOQ) of $0.7 \mu \mathrm{g} / \mathrm{L}$. Serum IFX and ATI were measured using a previously described commercially available homogenous mobility shift assay (Prometheus Laboratories, San Diego, California, USA). ${ }^{27}$ The LLOQ for the presence of IFX and ATI in this assay was $0.98 \mu \mathrm{g} / \mathrm{mL}$ and $3.13 \mathrm{U} / \mathrm{mL}$, respectively. By using a preanalytical acid dissociation step, this drug-tolerant assay can detect ATI in the presence of up to $60 \mu \mathrm{g} / \mathrm{mL} \mathrm{IFX.}{ }^{27}$ To reduce variability, all of the samples were reanalysed in batch.

\section{Statistical analyses}

Receiver operating characteristic (ROC) curves were used to determine the IFX and ATI concentration thresholds that best discriminated remission, defined as a CRP concentration of $\leq 5 \mathrm{mg} / \mathrm{L}$. The AUC of the ROC curve along with the $95 \% \mathrm{CI}$ were adjusted for repeated observations per subject. ${ }^{28} \mathrm{~A}$ multivariable logistic model assessed multiple clinical and laboratory factors as independent predictors of a CRP concentration of $>5 \mathrm{mg} / \mathrm{L}$. Factors included in the modelling process were study, gender, age at diagnosis, age at collection, days since first IFX infusion, age at first IFX, methotrexate use, azathioprine use, IFX concentration $<3 \mu \mathrm{g} / \mathrm{mL}$, ATI concentration $\geq 3.13 \mathrm{U} / \mathrm{mL}$ and an IFX-ATI interaction term. Factors not significant at the 0.05 level were removed by backwards elimination. A 
multivariable logistic model evaluated IFX concentration $<3 \mu \mathrm{g} /$ $\mathrm{mL}$, ATI concentration $\geq 3.13 \mathrm{U} / \mathrm{mL}$ and interval (days in-between samples) in a 'current sample' as independent predictors of a CRP concentration of $>5 \mathrm{mg} / \mathrm{L}$ in a 'future sample'. Only samples with an interval of $56 \pm 14$ days in-between 'current' and 'future' sample were taken into account for each patient. Two-way and three-way interactions between all the variables IFX, ATI and interval between samples were included in the model to investigate whether the effects of IFX and ATI were dependent on each other and dependent on time. The model was adjusted for study, days between first IFX and first sample and baseline CRP in the 'current' sample. All models were adjusted for multiple observations per subject, as a random effect.

\section{Ethical considerations}

All serum samples analysed were obtained during the execution of four separate parent clinical trials. The informed consent process complied with the International Conference on Harmonisation-Good clinical practice and all applicable regulatory requirement(s). The consent of subjects included the use of the collected data and serum for other medical purposes. Therefore, additional consent for the current study was not obtained. Each study was reviewed by a research ethics board at the respective site where the initial study was conducted (Western University for the COMMIT Trial and the Canadian Multicentre Trial, and the University of Leuven for the transient ATI study and the antimetabolite withdrawal study). All subject information used in this study was de-identified with respect to the subject identification number and investigational site. The serum samples were assayed following conclusion of the four original parent studies and did not affect patients' treatment and/or well-being.

\section{RESULTS}

\section{Study population}

Samples from 483 patients were analysed, of whom 236 $(48.9 \%)$ were men. The mean age of the patients at diagnosis was $28.5 \pm 12.9$ years. Eighty-five patients $(17.6 \%)$ received concomitant treatment with methotrexate while 140 patients (29\%) received concomitant azathioprine. A total of 1487 serum samples were analysed with a median of 2 (range 1-26) samples per patient. Demographic information and sample characteristics are summarised in table 1.

Overall the median (IQR) CRP concentration of the sample cohort was 3.6 (IQR $1.0-12.7$ ) $\mathrm{mg} / \mathrm{L}$. Of the 1487 serum samples, 6.5\% $(\mathrm{n}=96)$ were IFX and ATI negative, 69.8\% $(\mathrm{n}=1038)$ were IFX positive and ATI negative, 16.4\% $(\mathrm{n}=244)$ were IFX negative and ATI positive and 7.3\% $(n=109)$ were both IFX and ATI positive (figure 1). Samples that were positive for ATI had a significantly lower likelihood of having detectable IFX compared with ATI-negative samples (OR 0.041; 95\% CI 0.030 to $0.056 ; \mathrm{p}<0.001)$.

\section{Outcomes}

Based on ROC curve analysis, an IFX concentration cut-off of $>2.79 \mu \mathrm{g} / \mathrm{mL}$ (AUC=0.681; 95\% CI 0.632 to 0.731 ) was associated with remission $(77.6 \%$ specificity, $52.5 \%$ sensitivity), as seen in figure 2. When the IFX trough concentration was divided into quartiles, a significant concentration-dependent effect was observed on CRP concentration $(\mathrm{p}<0.001$ ) (figure $3 \mathrm{~A}$ ) and a linear trend was observed $(\mathrm{p}<0.001)$.

Based on ROC curve analysis, an ATI concentration cut-off of $<3.15 \mathrm{U} / \mathrm{mL}$ (AUC=0.632; 95\% CI 0.589 to 0.676 ) was associated with remission $(87.4 \%$ specificity, $38.0 \%$ sensitivity). Only taking ATI-positive samples into account $(\mathrm{n}=342)$, after stratification per quartile, a concentration-dependent trend was observed on CRP concentration $(p=0.07)$ (figure 3B). Moreover, a significant linear relationship was found, explaining that at least a part of the association with CRP can be explained by a trend across the four ATI quartiles $(p=0.025)$. Combining both factors IFX and ATI as predictors of disease activity increased the AUC of the ROC curve to 0.701.

Overall, 117 out of 483 patients (24.2\%) had detectable ATI on at least one time point during follow-up. The median CRP concentration was lower in ATI-negative samples compared with ATI-positive samples (respectively 2.4 vs. $11.9 \mathrm{mg} / \mathrm{L} ; \mathrm{p}<0.001$ ). In ATI-negative samples stratified according to IFX concentration, the median CRP concentration was significantly lower when the serum IFX concentration was $\geq 3 \mu \mathrm{g} / \mathrm{mL}$ compared with $<3 \mu \mathrm{g} / \mathrm{mL}$ (respectively 2.0 vs. $6.0 \mathrm{mg} / \mathrm{L} ; \mathrm{p}<0.001$ ). However, in ATI-positive samples, the median CRP concentration was similar in these two groups (respectively 11.9 vs. $11.6 \mathrm{mg} / \mathrm{L}$ ), although significantly different after correcting for multiple observations per patient $(p=0.019)$ (figure 4). In an exploratory analysis, omitting the samples from the Leuven transient ATI study, we found that CRP concentrations were numerically lower but the same effect was observed, in that CRP concentrations were elevated in ATI-positive samples despite an IFX concentration of $\geq 3 \mu \mathrm{g} / \mathrm{mL} \quad(7.9 \mathrm{mg} / \mathrm{L})$ or $<3 \mu \mathrm{g} / \mathrm{mL}$ $(9.2 \mathrm{mg} / \mathrm{L})(\mathrm{p}=0.004)$.

Univariate analyses demonstrated significant associations between originating study, presence of ATI and IFX concentration and the presence of active disease (CRP concentration $>5 \mathrm{mg} / \mathrm{L}$ ). However, multivariable analysis retained IFX $<3 \mu \mathrm{g} /$ $\mathrm{mL}$ (OR $1.8 ; 95 \%$ CI 1.3 to $2.5 ; \mathrm{p}<0.001$ ) and detectable ATI $(\geq 3.15 \mathrm{U} / \mathrm{mL})(\mathrm{OR} 1.8 ; 95 \%$ CI 1.2 to $2.6 ; \mathrm{p}=0.002)$ as the only independent predictors of this outcome. The interaction between IFX and ATI concentrations was also evaluated and was not significant $(p=0.116)$. For the multivariable logistic model evaluating IFX, ATI and interval (between samples) in a 'current' sample as independent predictors of a CRP concentration of $>5 \mathrm{mg} / \mathrm{L}$ in a 'future' sample, there were 454 patients with a complete set of IFX, ATI and CRP on at least two consecutive time points with no more than $56 \pm 14$ days in-between samples. After correcting for study, days between first IFX and first sample and baseline CRP, we observed that both IFX $<3 \mu \mathrm{g} / \mathrm{mL}(\mathrm{p}=0.035)$ and ATI $\geq 3.13 \mathrm{U} / \mathrm{mL}(\mathrm{p}=0.006)$ in a 'current' sample were able to predict a CRP concentration of $>5 \mathrm{mg} / \mathrm{L}$ in a 'future' sample. The interval between 'current' and 'future' sample was not found to be a predictor of CRP $(\mathrm{p}=0.466)$. IFX and ATI were found to independently predict CRP and independent of the time in-between samples as none of the two-way or three-way interactions between the variables IFX, ATI and interval between samples were significant.

\section{DISCUSSION}

This study, which evaluated 1487 trough serum samples from 483 patients with CD who received maintenance IFX therapy in four parent studies, to our knowledge is the largest evaluation of the relationship between IFX trough concentrations, ATI and clinical efficacy that has been reported. Importantly, the use of a drug-tolerant assay allowed us to assess the relevance of detection of ATI in the presence of an adequate IFX trough concentration.

These results confirm the existence of a strong inverse correlation between IFX trough concentration and CRP-defined remission. Notably, a linear test for trend was highly significant 
Table 1 Patient demographics within each study and the combined data set*

\begin{tabular}{|c|c|c|c|c|c|}
\hline & COMMIT & Canadian multicentre & Transient ATI & $\begin{array}{l}\text { IMM } \\
\text { withdrawal }\end{array}$ & Combined \\
\hline \multicolumn{6}{|l|}{ Patients } \\
\hline Patients-no. & 49 & 327 & 25 & 82 & 483 \\
\hline Men-no. (\%) & $28(57)$ & $157(48)$ & $11(44)$ & $40(49)$ & $236(49)$ \\
\hline Age at diagnosis & $29.5 \pm 13.3$ & $29.3 \pm 13.2$ & $26.8 \pm 11.6$ & $25.5 \pm 11.3$ & $28.5 \pm 12.9$ \\
\hline Age at first sample collection & $39.0 \pm 14.0$ & $39.9 \pm 12.9$ & $40.3 \pm 12.7$ & $35.7 \pm 13.8$ & $39.1 \pm 13.2$ \\
\hline Age at first infliximab & $38.6 \pm 14.1$ & $38.5 \pm 13.0$ & $39.9 \pm 12.5$ & $33.7 \pm 13.8$ & $37.7 \pm 13.3$ \\
\hline Patients ever IFX $\geq 3 \mu \mathrm{g} / \mathrm{mL}$-no. (\%) & $44(90)$ & $237(73)$ & $15(60)$ & $75(92)$ & $371(77)$ \\
\hline Patients ever ATI positive-no. (\%) & $9(18)$ & $73(22)$ & $23(92)$ & $12(15)$ & $117(24)$ \\
\hline Patients ever receiving MTX—no. (\%) & $23(47)$ & $30(9)$ & $9(36)$ & $23(28)$ & $85(18)$ \\
\hline Patients ever receiving AZA-no. (\%) & $0(0)$ & $81(25)$ & $0(0)$ & $59(72)$ & $140(29)$ \\
\hline \multicolumn{6}{|l|}{ Serum samples } \\
\hline Serum samples-no. & 169 & 637 & 314 & 367 & 1487 \\
\hline Samples per subject $^{\dagger}$ & $4(1-4)$ & $2(1-2)$ & $11(2-26)$ & $4(1-13)$ & $2(1-26)$ \\
\hline Time between first infliximab and sample-months ${ }^{\dagger}$ & $7(6.5-9)$ & $17(11-26)$ & $17(9-40)$ & $24(17-50)$ & $17(9-29)$ \\
\hline Serum samples IFX $\geq 3 \mu \mathrm{g} / \mathrm{mL}$-no. (\%) & $135(80)$ & $417(66)$ & $102(33)$ & $295(80)$ & $949(64)$ \\
\hline Serum samples ATI positive—no. (\%) & $19(11)$ & $115(18)$ & $183(58)$ & $36(10)$ & $353(24)$ \\
\hline $\mathrm{CRP}-\mathrm{mg} / \mathrm{L}$ & $5.9 \pm 11.1$ & $11.2 \pm 22.9$ & $24.4 \pm 32.5$ & $8.5 \pm 13.8$ & $12.6 \pm 23.2$ \\
\hline $\mathrm{CRP}^{\dagger}-\mathrm{mg} / \mathrm{L}$ & $2.1(0.8-6.2)$ & $3.0(0.8-10.0)$ & $11.7(3.1-29.7)$ & $2.4(0.7-9.7)$ & $3.6(1.0-12.7)$ \\
\hline
\end{tabular}

for these factors supporting the presence of an 'exposure-effect relationship'. In ROC curve analysis, an IFX trough concentration of $\leq 2.79 \mu \mathrm{g} / \mathrm{mL}$ best discriminated disease activity (OR 2.13 ; $95 \%$ CI 1.54 to 2.96 ), suggesting that this value can be used as a benchmark in clinical practice; however, confirmatory studies are needed. Prospectively acquired data re-confirming this threshold would provide additional validity.

This study also provides new insights into the relationship between ATI and disease activity. Use of the drug-tolerant fluid phase mobility shift assay allowed us to assess the role of ATI in the presence of IFX. A strong correlation was observed between

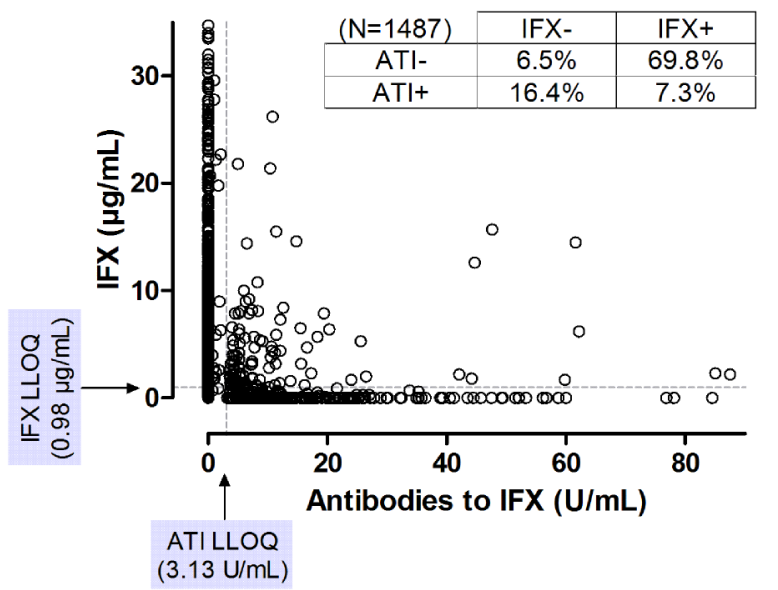

Figure $1 \mathrm{XY}$ plot of infliximab (IFX) and antibody to infliximab (ATI) concentration of all 1487 samples. Lower limit of quantitation (LLOQ) for IFX and ATI using the homogenous mobility shift assay was respectively $0.98 \mu \mathrm{g} / \mathrm{mL}$ and $3.13 \mathrm{U} / \mathrm{mL}$. Seventeen data points were outside the axis limits: $4 / 17$ samples had IFX $>35 \mu \mathrm{g} / \mathrm{mL}$ (none were positive for ATI) and 13/17 samples had ATI $>90 \mathrm{U} / \mathrm{mL}$ (none were positive for IFX). Positive (+) and negative (-) signs represent respectively samples with detectable and undetectable IFX or ATI. the presence of ATI and the likelihood of active disease defined by a CRP concentration of $>5 \mathrm{mg} / \mathrm{L}$. Interestingly, a linear test for trend for CRP concentration across different ATI quartiles was significant, suggesting a 'causal relationship' between both these factors. ROC curve analysis revealed an ATI concentration of $\geq 3.15 \mathrm{U} / \mathrm{mL}$ best discriminated active disease (OR 2.22; $95 \%$ CI 1.56 to 3.15 ). However, it was notable that in the subset of samples that were positive for ATI and also had an IFX trough concentration $\geq 3 \mu \mathrm{g} / \mathrm{mL}$, a similar proportion of samples had CRP $>5 \mathrm{mg} / \mathrm{L}$ compared with the subset of samples that were ATI positive and had an IFX trough concentration $<3 \mu \mathrm{g} / \mathrm{mL}$

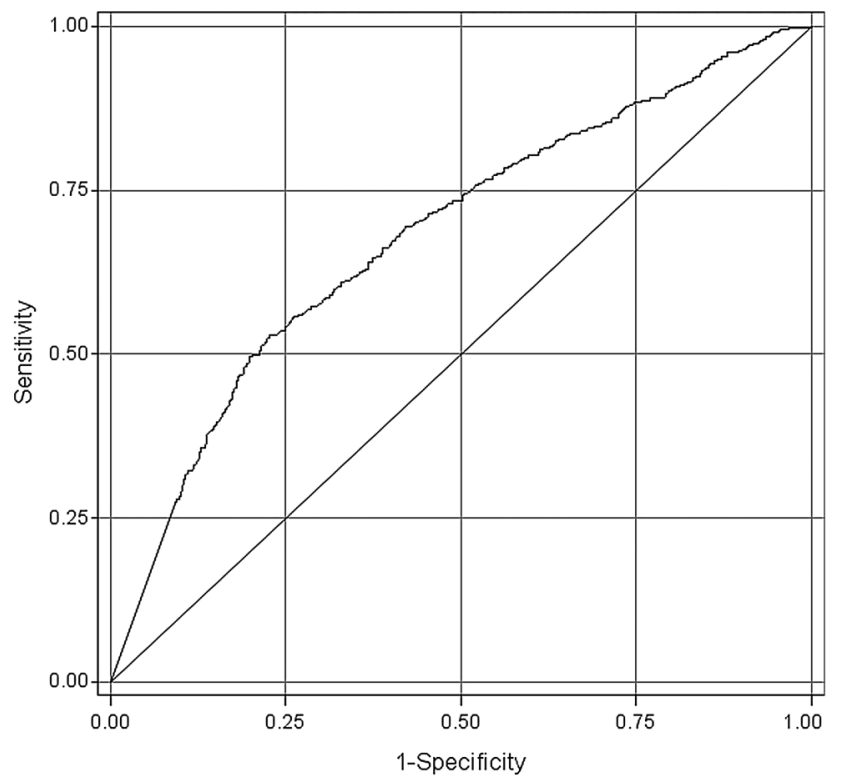

Figure 2 Receiver operating characteristic curve analysis showing the infliximab threshold that best discriminated disease activity, as measured by C-reactive protein (concentration $\leq 5 \mathrm{mg} / \mathrm{L}$ was defined as inactive disease). 

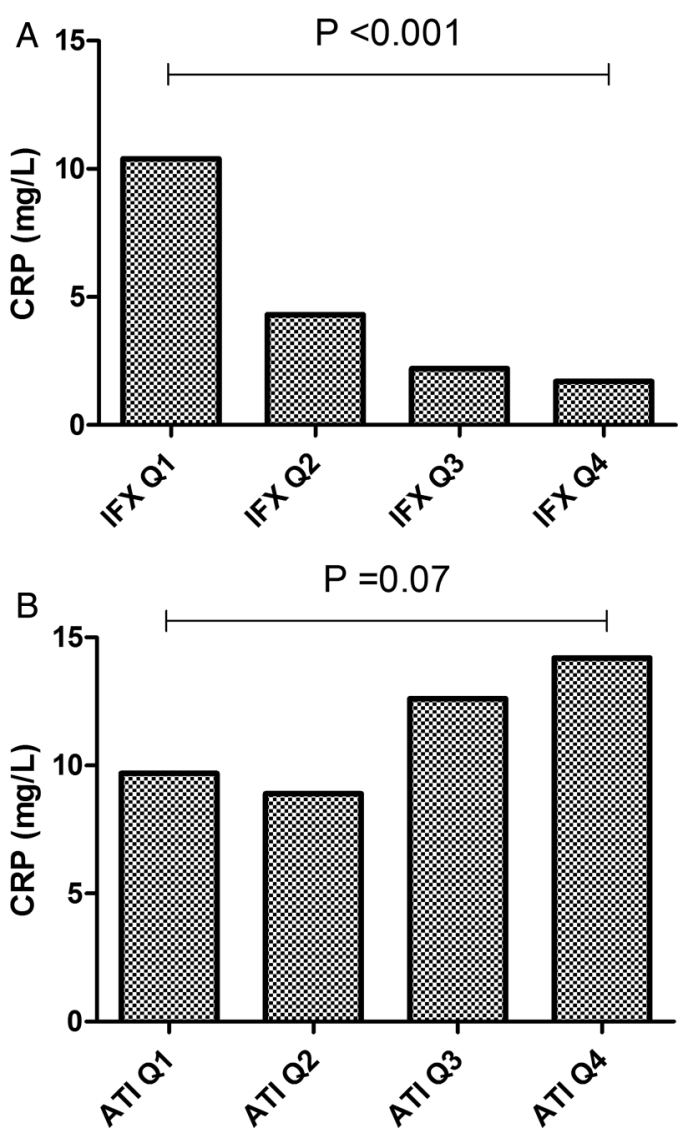

Figure 3 Median C-reactive protein (CRP) concentration $(\mathrm{mg} / \mathrm{L})$ per quartile of infliximab trough (IFX) concentration (A) and antibody to infliximab (ATI) concentration (B). IFX concentration $(\mu \mathrm{g} / \mathrm{mL})$ quartiles (Q) were Q1 $<1.27 ;$ Q2 $\geq 1.27$ to $<4.68 ;$ Q3 $\geq 4.68$ to $<8.59$ and Q4 $\geq 8.59$ and ATI concentration quartiles (Q) for ATI-positive samples were Q1 $<6.23 ;$ Q2 $\geq 6.23$ to $<11.32 ;$ Q3 $\geq 11.32$ to $<21.06$ and Q4 $\geq 21.06$.

(respectively $36 / 54$ samples (66.7\%) vs. 199/288 samples $(69.1 \%) ; p=0.084)$. Consistent with this observation, the presence of ATI was confirmed as an independent predictor of

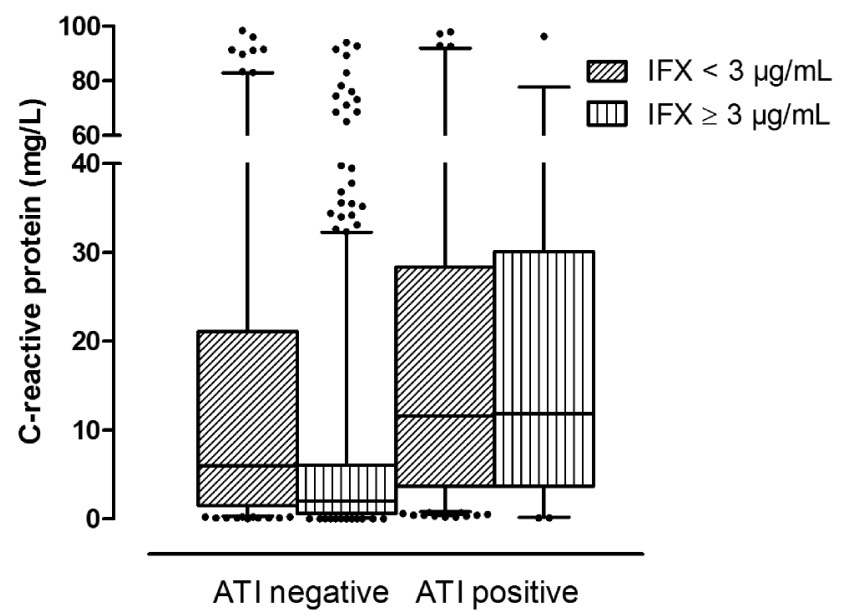

Figure 4 Whiskers boxplot (5th-95th centile) representing the C-reactive protein concentration $(\mathrm{mg} / \mathrm{L})$ in samples with an infliximab (IFX) trough concentration above or below the threshold of $3 \mu \mathrm{g} / \mathrm{mL}$, both for antibody to IFX (ATI) negative $(<3.13 \mathrm{U} / \mathrm{mL})$ and ATI positive $(\geq 3.13 \mathrm{U} / \mathrm{mL}$ ) samples. active disease in the multivariable model. This observation suggests that ATI negatively influence the efficacy of IFX even in low concentrations and in the presence of an adequate trough drug concentration. These results point towards an alternative mechanism of action of how ATI impair drug activity as it was previously thought that this was mainly driven by an effect on the pharmacokinetics of the drug causing a faster clearance. Our results support the hypothesis that at least in some patients the effect of ATI is mediated through binding of the ATI to the idiotype of IFX, thereby blocking the binding to tumour necrosis factor (TNF) and directly neutralising the drug's activity. Most likely, in the majority of patients, it is a combination of both mechanisms that will ultimately lead to impaired drug activity. In fact, it is believed that when only one or two endogenous antidrug antibodies bind to an exogenous protein, this has no effect on its half-life and may actually increase and approach that of endogenous IgG. On the other hand, when three or more endogenous antidrug antibodies bind to the exogenous protein simultaneously, the resulting immune complex will be eliminated rapidly through phagocytosis, increasing the clearance and decreasing the half-life of the drug. ${ }^{29}$ Aside from characterising the neutralising capacity of endogenous antidrug antibodies and complex formation in vivo, future research should evaluate the role of other pharmacokinetic parameters such as the $\mathrm{AUC}^{30}$ and $\mathrm{C}_{\max }{ }^{31}$ as these might prove to be important determinants of the pharmacokinetic/pharmacodynamic relationship that are negatively affected by ATI.

Our study has several clinical implications. Identification of optimum IFX trough and ATI threshold concentrations should facilitate TDM using a drug-tolerant assay. Currently, the most common application of TDM is for the evaluation of patients with a secondary loss of response. In this paradigm, patients with subtherapeutic IFX concentrations who lack ATI may benefit from dose intensification. A second group consists of patients who are ATI negative and have an adequate IFX trough concentration. Although scientific evidence is lacking, inflammation in these individuals may be driven by processes that are not TNF dependent. Accordingly, a switch to an 'out of class' agent such as vedolizumab might be optimal. ${ }^{32}$ In a third group of patients, those with absent drug and a high concentration of ATI, a switch to another TNF antagonist is likely optimal since the patient originally responded to this class of drugs and, for the most part, ATI does not neutralise other agents. Finally, little is known regarding the optimal management of patients with detectable concentrations of both IFX and ATI. Dose escalation may be considered in those patients as well as a switch to another TNF antagonist as from our data it was observed that even low ATI in the presence of IFX are an independent predictor for elevated CRP ( $>5 \mathrm{mg} / \mathrm{L})$.

Apart from the emerging role in the management of patients with secondary loss of response, other important applications of TDM are likely to evolve including prospective dose optimisation with selective dose intensification or reduction. This strategy could improve therapeutic efficacy, reduce the risk of ATI formation and decrease the cost of care. ${ }^{18} 3334$ Studies such as the TAXIT and TAILORIX trials, in which patients are randomly assigned to standard care or to prospective dose optimisation based on TDM, have been initiated. The TAXIT trial showed that, during maintenance therapy with IFX, better clinical outcomes were achieved when a threshold IFX trough concentration of $\geq 3 \mu \mathrm{g} / \mathrm{mL}$ was targeted and that patients with an IFX trough concentration of $>7 \mu \mathrm{g} / \mathrm{mL}$ could be safely dose de-escalated, resulting in significantly lower drug costs without affecting the proportion of patients in remission. ${ }^{35}$ After this 
initial dose optimisation, no additional benefit was observed to continue concentration-based dosing over clinically based dosing throughout the first year. ${ }^{36}$ The prospectively acquired data from TAXIT confirm the IFX trough concentration threshold that was found here, and its validity across different assay formats as in the TAXIT trial a clinically validated ELISA was used to measure IFX concentrations. ${ }^{5}$

Our study had several limitations. First, it was retrospectively designed. However, data were derived from four parent cohorts that evaluated patients with CD receiving IFX maintenance therapy and where trough serum samples were prospectively collected. Second, disease activity was measured by CRP concentration, a biomarker for inflammation, rather than by the gold standard of colonoscopy. During the time the parent studies were designed, endoscopic evaluation was not routinely used as an outcome measure in clinical research. Nevertheless, CRP has previously been shown to be an accurate marker to predict reactivation of disease activity in patients with CD treated with IFX therapy. ${ }^{37}$ Finally, the IFX and ATI thresholds were not independently confirmed in a separate population of patient samples. This is an important limitation that will be redressed in a follow-up study.

In conclusion, we have defined trough IFX and ATI concentration thresholds that are independently associated with remission in CD. Further investigation into the mechanisms by which ATI negatively affect the efficacy of IFX and strategies to prevent the development of sensitisation are a research priority.

Contributors NVC: acquisition of data, analysis and interpretation of data, drafting of the manuscript; RK: drafting of the manuscript; BGL and GRG: critical revision of the manuscript for important intellectual content; LS and GYZ: statistical analysis; SS, SH and LO: technical or material support; SL: statistical analysis and interpretation of data; PJR: study concept and design, critical revision of the manuscript for important intellectual content; AG and WJS: interpretation of the data and critical revision of the manuscript for important intellectual content; SV: study concept and design, interpretation of the data and critical revision of the manuscript for important intellectual content; BGF: study concept and design, interpretation of data, critical revision of the manuscript for important intellectual content and study supervision.

Funding NVC is a Postdoctoral Fellow of the Research Foundation-Flanders (FWO), Belgium; grant number $1260714 \mathrm{~N}$ and a recipient of the United European Gastroenterology (UEG) Top Abstract Prize. This study was funded in part by a research grant from the Research Foundation-Flanders (FWO), Belgium; grant number G.0617.12. This study was funded in part by Prometheus Laboratories, San Diego, California, USA.

Competing interests NVC received speakers and consultancy fees from MSD, Janssen Biologics BV and Abbvie; RK received speakers fees from Abbvie and Takeda; BGL received consultancy fees from Abbvie, Prometheus, Nestle Health Sciences, Santarus and was on the speakers bureau of Warner Chilcott and UCB Pharma and is an employee of Robarts Clinical Trials; LS and GYZ are employees of Robarts Clinical Trials; SS, SL and SH are employees of Prometheus Laboratories; LO is a former employee of Prometheus Laboratories; GRG received speaker or consultancy fees from Janssen Canada, Merck, Prometheus Laboratories, and Abbott Laboratories, and has received research funding from UCB Pharma, Centocor, and Millennium Pharmaceuticals; PJR received research grants from Abbott, Abvie, Prometheus, MSD and UCB Pharma, lecture and consultant fees from Abbott, Abvie, MSD, UCB Pharma, Genentech, Millenium, Neovacs, Actogenics, Amgen, Prometheus, Bristol-Myers Squibb; AG received speakers fees from Pfizer, Janssen Biologics and MSD and investigator initiated research grants from Pfizer; WJS reports having received consulting fees from ActoGeniX NV, AGI Therapeutics, Alba Therapeutics Corporation, Albireo, Alfa Wasserman, Amgen, AM-Pharma BV, Anaphore, Astellas Pharma, Athersys, Atlantic Healthcare Limited, Axcan Pharma (now Aptalis), BioBalance Corporation, Boehringer-Ingelheim, Bristol Meyers Squibb, Celgene, Celek Pharmaceuticals, Cellerix SL, Cerimon Pharmaceuticals, ChemoCentryx, CoMentis, Cosmo Technologies, Coronado Biosciences, Cytokine Pharmasciences, Eagle Pharmaceuticals, Eisai Medical Research, Elan Pharmaceuticals, EnGene, Eli Lilly, Enteromedics, Exagen Diagnostics, Ferring Pharmaceuticals, Flexion Therapeutics, Funxional Therapeutics Limited, Genzyme Corporation, Genentech (now Roche), Gilead Sciences, Given Imaging, Glaxo Smith Kline, Human Genome Sciences, Ironwood Pharmaceuticals (previously Microbia), Janssen (previously Centocor), KaloBios Pharmaceuticals, Lexicon Pharmaceuticals,
Lycera Corporation, Meda Pharmaceuticals (previously Alaven Pharmaceuticals), Merck Research Laboratories, MerckSerono, Millennium Pharmaceuticals (subsequently merged with Takeda), Nisshin Kyorin Pharmaceuticals Co., Novo Nordisk A/S, NPS Pharmaceuticals, Optimer Pharmaceuticals, Orexigen Therapeutics, PDL Biopharma, Pfizer, Procter and Gamble, Prometheus Laboratories, ProtAb Limited, Purgenesis Technologies, Receptos, Relypsa, Salient Pharmaceuticals, Salix Pharmaceuticals, Santarus, Schering Plough Corporation (acquired by Merck), Shire Pharmaceuticals, Sigmoid Pharma Limited, Sirtris Pharmaceuticals (a GSK company), S.L.A. Pharma (UK) Limited, Targacept, Teva Pharmaceuticals, Therakos, Tillotts Pharma AG (acquired by Zeria Pharmaceutical Co.), TxCell SA, UCB Pharma, Viamet Pharmaceuticals, Vascular Biogenics Limited (VBL), Warner Chilcott UK Limited, Wyeth (now Pfizer); has received lecture fees from Bristol Meyers Squibb, and Janssen (previously Centocor); and has received research support from Bristol Meyers Squibb, Genentech, Glaxo Smith Kline, Janssen (previously Centocor), Millennium Pharmaceuticals (now Takeda), Novartis, Pfizer, Procter and Gamble Pharmaceuticals, Shire Pharmaceuticals, and UCB Pharma; SV received financial support for research from UCB Pharma, Abbvie and UCB Pharma, lecture fees from Abbott, Abbvie, MSD, Ferring Pharmaceuticals and UCB Pharma and consultancy fees from Pfizer, Ferring Pharmaceuticals, Shire Pharmaceuticals Group, MSD, and AstraZeneca Pharmaceuticals; BGF has served as a speaker for Abbott/AbbVie, JnJ/ Janssen, Takeda, Warner-Chilcott, UCB Pharma, a consultant for Abbott/AbbVie, Actogenix, Albireo Pharma, Amgen, Astra Zeneca, Avaxia Biologics, Axcan, Baxter Healthcare Corp., Boehringer-Ingelheim, Bristol-Myers Squibb, Calypso Biotech, Celgene, Elan/Biogen, EnGene, Ferring Pharma, Roche/Genentech, GiCare Pharma, Gilead, Given Imaging, GSK, Ironwood Pharma, Janssen Biotech (Centocor), JnJ/ Janssen, Kyowa Kakko Kirin Co., Lexicon, Lilly, Merck, Millennium, Nektar, Novonordisk, Pfizer, Prometheus Therapeutics and Diagnostics, Protagonist, Receptos, Salix Pharma, Serono, Shire, Sigmoid Pharma, Synergy Pharma, Takeda, Teva Pharma, Tillotts, UCB Pharma, Vertex Pharma, Warner-Chilcott, Wyeth, Zealand, Zyngenia, and has received research funding from Abbott/AbbVie, Amgen, Astra Zeneca, Bristol-Myers Squibb (BMS), Janssen Biotech (Centocor), JnJ/Janssen, Roche/Genentech, Millennium, Pfizer, Receptos, Santarus, Sanofi, Tillotts, UCB Pharma and is an employee of Robarts Clinical Trials.

Ethics approval Investigational review board at each participating centre of the four combined parent clinical studies.

Provenance and peer review Not commissioned; externally peer reviewed.

Open Access This is an Open Access article distributed in accordance with the Creative Commons Attribution Non Commercial (CC BY-NC 4.0) license, which permits others to distribute, remix, adapt, build upon this work non-commercially, and license their derivative works on different terms, provided the original work is properly cited and the use is non-commercial. See: http://creativecommons.org/ licenses/by-nc/4.0/

\section{REFERENCES}

1 Baert $F$, Noman $M$, Vermeire $S$, et al. Influence of immunogenicity on the long-term efficacy of infliximab in Crohn's disease. N Engl J Med 2003;348:601-8.

2 Steenholdt C, Bendtzen K, Brynskov J, et al. Cut-off levels and diagnostic accuracy of infliximab trough levels and anti-infliximab antibodies in Crohn's disease. Scand J Gastroenterol 2011;46:310-18.

3 Vande Casteele N, Gils A, Singh S, et al. Antibody response to infliximab and its impact on pharmacokinetics can be transient. Am J Gastroenterol 2013;108:962-71.

4 Steenholdt C, Ainsworth MA, Tovey M, et al. Comparison of techniques for monitoring infliximab and antibodies against infliximab in Crohn's disease. Ther Drug Monit 2013:35:530-8.

5 Vande Casteele N, Buurman DJ, Sturkenboom MGG, et al. Detection of infliximab levels and anti-infliximab antibodies: a comparison of three different assays. Aliment Pharmacol Therap 2012;36:765-71.

6 Ungar B, Chowers Y, Yavzori M, et al. The temporal evolution of antidrug antibodies in patients with inflammatory bowel disease treated with infliximab. Gut 2014:63:1258-64.

7 Steenholdt C, Al-Khalaf M, Brynskov J, et al. Clinical implications of variations in anti-infliximab antibody levels in patients with inflammatory bowel disease. Inflamm Bowel Dis 2012;18:2209-17.

8 Nanda KS, Cheifetz AS, Moss AC. Impact of antibodies to infliximab on clinical outcomes and serum infliximab levels in patients with inflammatory bowel disease (IBD): a meta-analysis. Am J Gastroenterol 2013;108:40-7

9 Seow $\mathrm{CH}$, Newman A, Irwin SP, et al. Trough serum infliximab: a predictive factor of clinical outcome for infliximab treatment in acute ulcerative colitis. Gut 2010:59:49-54

10 Maser EA, Villela R, Silverberg MS, et al. Association of trough serum infliximab to clinical outcome after scheduled maintenance treatment for Crohn's disease. Clin Gastroenterol Hepatol 2006;4:1248-54.

11 Bortlik M, Duricova D, Malickova K, et al. Infliximab trough levels may predict sustained response to infliximab in patients with Crohn's disease. J Crohns Colitis 2013;7:736-43 
12 Karmiris K, Paintaud G, Noman M, et al. Influence of trough serum levels and immunogenicity on long-term outcome of adalimumab therapy in Crohn's disease. Gastroenterology 2009;137:1628-40.

13 Baert F, Drobne D, Gils A, et al. Early trough levels and antibodies to infliximab predict safety and success of reinitiation of infliximab therapy. Clin Gastroenterol Hepatol 2014;12:1474-1481.e2.

14 Roblin X, Marotte $\mathrm{H}$, Rinaudo $\mathrm{M}$, et al. Association between pharmacokinetics of adalimumab and mucosal healing in patients with inflammatory bowel diseases. Clin Gastroenterol Hepatol 2014;12:80-4.

15 Paul S, Del Tedesco E, Marotte $H$, et al. Therapeutic drug monitoring of infliximab and mucosal healing in inflammatory bowel disease: a prospective study. Inflamm Bowel Dis 2013;19:2568-76.

16 Hanauer SB, Feagan BG, Lichtenstein GR, et al. Maintenance infliximab for Crohn's disease: the ACCENT I randomised trial. Lancet 2002;359:1541-9.

17 Cornillie F, Hanauer SB, Diamond RH, et al. Postinduction serum infliximab trough level and decrease of $C$-reactive protein level are associated with durable sustained response to infliximab: a retrospective analysis of the ACCENT I trial. Gut 2014;63:1721-7

18 Steenholdt C, Brynskov J, Thomsen 00, et al. Individualised therapy is more costeffective than dose intensification in patients with Crohn's disease who lose response to anti-TNF treatment: a randomised, controlled trial. Gut 2014;63:919-27.

19 Afif W, Loftus EV Jr, Faubion WA, et al. Clinical utility of measuring infliximab and human anti-chimeric antibody concentrations in patients with inflammatory bowel disease. Am J Gastroenterol 2010;105:1133-9.

20 Vande Casteele N, Feagan BG, Gils A, et al. Therapeutic drug monitoring in inflammatory bowel disease: current state and future perspectives. Curr Gastroenterol Rep 2014;16:378.

21 Ben-Horin S, Chowers Y. Tailoring anti-TNF therapy in IBD: drug levels and disease activity. Nat Rev Gastroenterol Hepatol 2014;11:243-55.

22 Mao R, Xiao YL, Gao X, et al. Fecal calprotectin in predicting relapse of inflammatory bowel diseases: a meta-analysis of prospective studies. Inflamm Bowel Dis 2012;18:1894-9.

23 Peyrin-Biroulet L, Reinisch W, Colombel JF, et al. Clinical disease activity, C-reactive protein normalisation and mucosal healing in Crohn's disease in the SONIC trial. Gut 2014;63:88-95.

24 Feagan BG, McDonald JW, Panaccione R, et al. Methotrexate in combination with infliximab is no more effective than infliximab alone in patients with Crohn's disease. Gastroenterology 2014;146:681-8.
25 Levesque BG, Greenberg GR, Zou G, et al. A prospective cohort study to determine the relationship between serum infliximab concentration and efficacy in patients with luminal Crohn's disease. Aliment Pharmacol Ther 2014;39:1126-35.

26 Drobne D, Bossuyt P, Breynaert C, et al. Withdrawal of Immunomodulators After Co-treatment Does not Reduce Trough Level of Infliximab in Patients with Crohn's Disease. Clin Gastroenterol Hepatol. Published Online First: 24 July 2014. doi:10. 1016/j.cgh.2014.07.027

27 Wang SL, Ohrmund L, Hauenstein S, et al. Development and validation of a homogeneous mobility shift assay for the measurement of infliximab and antibodies-to-infliximab levels in patient serum. $J$ Immunol Methods 2012;382:177-88.

28 Obuchowski NA. Nonparametric analysis of clustered ROC curve data. Biometrics 1997;53:567-78.

29 Rehlaender BN, Cho MJ. Antibodies as carrier proteins. Pharm Res 1998;15:1652-6.

30 Brandse JF, van der Kleij D, Wolbink G-J, et al. 786 the pharmacokinetics of infliximab induction therapy in patients with moderate to severe ulcerative colitis. Gastroenterology 2014;146:S-134.

31 Yamada A, Sono K, Hosoe $\mathrm{N}$, et al. Monitoring functional serum antitumor necrosis factor antibody level in Crohn's disease patients who maintained and those who lost response to anti-TNF. Inflamm Bowel Dis 2010;16:1898-904.

32 Sandborn WJ, Feagan BG, Rutgeerts $P$, et al. Vedolizumab as induction and maintenance therapy for Crohn's disease. N Engl J Med 2013;369:711-21.

33 Velayos FS, Kahn JG, Sandborn WJ, et al. A test-based strategy is more cost effective than empiric dose escalation for patients with Crohn's disease who lose responsiveness to infliximab. Clin Gastroenterol Hepatol 2013;11:654-66.

34 Krieckaert CL, Nair SC, Nurmohamed MT, et al. Personalised treatment using serum drug levels of adalimumab in patients with rheumatoid arthritis: an evaluation of costs and effects. Ann Rheum Dis 2015;74:361-8.

35 Vande Casteele N, Compernolle G, Ballet V, et al. OP11 Individualised infliximab treatment using therapeutic drug monitoring: a prospective controlled Trough level Adapted infliXImab Treatment (TAXIT) trial. J Crohns Colitis 2012;6:S6.

36 Vande Casteele N, Gils A, Ballet V, et al. OP001 Randomised controlled trial of drug level versus clinically based dosing of infliximab maintenance therapy in IBD: final results of the TAXIT study. United European Gastroenterol J 2013;1:A1.

37 Jürgens $\mathrm{M}$, Mahachie John JM, Cleynen I, et al. Levels of C-reactive protein are associated with response to infliximab therapy in patients with Crohn's disease. Clin Gastroenterol Hepatol 2011;9:421-7. 